University of Warwick institutional repository: http://go.warwick.ac.uk/wrap

This paper is made available online in accordance with

publisher policies. Please scroll down to view the document

itself. Please refer to the repository record for this item and our

policy information available from the repository home page for

further information.

To see the final version of this paper please visit the publisher's website. access to the published version may require a subscription.

Author(s): Eric B. Holub

Article Title: Natural history of Arabidopsis thaliana and oomycete

symbioses

Year of publication: 2008

Link to published version: http://dx.10.1007/s10658-008-9286-1

Publisher statement: 


\title{
Natural history of Arabidopsis thaliana and oomycete symbioses
}

\author{
Eric B. Holub
}

Received: 3 September 2007 / Accepted: 31 January 2008

(C) KNPV 2008

\begin{abstract}
Molecular ecology of plant-microbe interactions has immediate significance for filling a gap in knowledge between the laboratory discipline of molecular biology and the largely theoretical discipline of evolutionary ecology. Somewhere in between lies conservation biology, aimed at protection of habitats and the diversity of species housed within them. A seemingly insignificant wildflower called Arabidopsis thaliana has an important contribution to make in this endeavour. It has already transformed botanical research with deepening understanding of molecular processes within the species and across the Plant Kingdom; and has begun to revolutionize plant breeding by providing an invaluable catalogue of gene sequences that can be used to design the most precise molecular markers attainable for markerassisted selection of valued traits. This review describes how $A$. thaliana and two of its natural biotrophic parasites could be seminal as a model for exploring the biogeography and molecular ecology of plant-microbe interactions, and specifically, for testing hypotheses proposed from the geographic mosaic theory of co-evolution.
\end{abstract}

E. B. Holub $(\bowtie)$

Warwick-HRI, University of Warwick,

Wellesbourne CV35 9EF, UK

e-mail: eric.holub@warwick.ac.uk
Keywords Hyaloperonospora parasitica . Albugo candida . Downy mildew . White blister rust . Gene-for-gene $\cdot$ Innate immunity $\cdot$ Receptor-like proteins - Arms race $\cdot$ LRR - CATERPILLAR genes . Boechera $\cdot$ Geographic mosaic $\cdot$ Non-host resistance

\section{Introduction}

In the current age of molecular technology and big science questions, the practical aims for downy mildew research have remained essentially unchanged for more than a century. Investment in downy mildew research still seeks practical solutions for improved disease control, through better use of fungicides and to aid the breeding and deployment of downy mildew resistant crops.

Plant breeding, however, has been transformed over the past 20 years by molecular genetics, which has been providing knowledge of the genes that underlie natural variation in valued traits of species such as Arabidopsis thaliana, tomato and rice. Converting valued traits into knowledge of genes is an important step for genetic engineering, but more importantly, it provides the means to design the most precise molecular markers attainable for markerassisted selection of valued traits in conventional breeding programmes (McCouch 2004). From the initial public investment in research, the knowledge gained has potential use across breeding efforts in different plant species. For instance, molecular genetics 
led to the discovery of numerous pathogen receptorlike genes that provide the molecular basis for downy mildew resistance in A. thaliana (Holub 2001, 2007). These major discoveries in turn have been instrumental in the early development of marker-assisted selection for disease resistance in crops (Aarts et al. 1998a; Botella et al. 1997; Michelmore and Wong 2008; Shen et al. 2002; Speulman et al. 1998).

In a similar process of scientific enquiry, conservation biology could also benefit significantly from the assimilation of molecular genetics research. Progress has been and will continue to be achieved in the protection of biological diversity without knowing much detail about the genetic variation within species. However, by analogy with the recent advances in plant breeding, knowledge about critical genes (e.g., that enable adaptability of a species) could provide useful indicators for improving the prospects for survival of animal and plant populations that are in most need of protection.

For example, the geographic mosaic theory of coevolution has been proposed to explain how intimate interactions among multiple species will co-evolve across geographic landscapes and provides a major process in organising the earth's biodiversity (Thompson 1999a, b; Gomulkiewicz et al. 2007). The theory proposes a three-part hypothesis: (a) the species interactions will have different evolutionary trajectories in different populations thereby generating a selection mosaic of co-evolving traits among populations; (b) some of the interacting populations will be hot spots for reciprocal selection of the coevolving traits, whereas cold spots will also be generated in which selection is unilateral or not occurring at all; and, (c) continual re-mixing of traits will occur across the geographic landscape (e.g., gene flow, genetic drift and local extinction of populations). Understanding the molecular basis of coevolving traits will be essential for empirical testing of this tripartite hypothesis, for providing fundamental advances in evolutionary ecology, and ultimately for providing invaluable insight that will aid the more practical domain of conservation biology.

The purpose of this review is to describe how A. thaliana and two of its natural biotrophic parasites could be seminal as a model for exploring the biogeography and molecular ecology of plantmicrobe interactions, and specifically, for testing hypotheses proposed from the geographic mosaic theory of coevolution. This subject is relatively young, but stands on the shoulders of important biologists whose contributions provide a foundation for this review.

\section{Divergent enquiry from early revolutions in plant science}

Natural history and molecular biology have developed as polar disciplines (Wilson 1994; see 'Molecular wars' chapter, pp. 218-237), determined by the environments in which the respective practitioners have generally explored their chosen subjects (field versus laboratory), and contrasting methodologies. They also differ markedly in the relative accessibility to amateur biologists and a public audience.

Molecular biology is rooted in a revolution of experimental science that began in the mid-1800s and led by European scientists including the botanists Anton DeBary in Germany and Harry Marshall Ward in England (Ayers 2005). Their dream was 'the Cause', a new approach to botany that could equal chemistry and physics as a rigorous, experimental science. They incorporated both field observations and laboratory experiments in their studies of plantmicrobe interactions catalyzed by the invention of light microscopy but pre-dating genetics. Biochemistry and biophysics would eventually provide a strong basis for experimental botany, as with the whole of biology. However, Gregor Mendel's discovery of genetics from his seminal experiments with plants soon provided a fundamental mathematical rigour that is unique to biology. It was therefore fitting that the 2nd International Downy Mildew conference was held in central Europe, and specifically in Olomouc, Czech Republic where Mendel had been a student and near the monastery in Brno where he conducted his now famous experiments.

Genetics is the cornerstone of molecular biology, used to illuminate the cause and effect mechanisms of proteins within organisms under strict laboratory environments. In recent years, whole genome sequences have become publicly available from pioneering use of species like A. thaliana and Phytophthora sojae. And, this in turn has galvanized a Linnaeanlike approach by an international community of molecular biologists to name and classify all of the proteins encoded within an organism, one representa- 
tive organism at a time (Clark et al. 2007; Holub 2006, 2007; Kamoun 2007; Tör 2008; Tyler et al. 2006; Win et al. 2007). This in effect is providing a powerful online catalogue of genes that enables further comparisons to be made among species (socalled comparative genomics). Researchers will continue to pursue their experiments largely in the laboratory. However, molecular biology is increasingly being enriched by biometricians and mathematicians who are enabling extrapolation of what has been learned from biochemical mechanisms in model organisms into other less tractable species, and predictive modelling in the emerging field of molecular systems biology which aims to advance understanding of the cause and effect associations amongst molecules of cellular processes (Holub 2007; Jönsson et al. 2006; Prusinkiewicz et al. 2007).

Natural history, on the other hand, is transforming into evolutionary ecology in its modern research form (Thompson et al. 2001). This young cross-discipline is rooted in comparative methods and mathematical modelling as its cornerstones, and builds on ecology as the ultimate arena for 'systems biology' research (Wilson 1994). Evolutionary ecology has progressed from the early revolutions led by Karl Linnaeus (the founder of taxonomy) and Charles Darwin (the founder of evolutionary theory) into a molecular age of being able to, for example, reassess classifications of species through the inference of familial history (or phylogenetics) of species with comparative analyses of informative DNA, RNA and protein sequences.

Phylogenetic trees provide the structure for bold new ventures led by evolutionary biologists, ecologists and amateur taxonomists to assemble information on the earth's biodiversity in online encyclopaedias (www.eol. org; www.tolweb.org; www.nbn.org.uk). These publicly accessible libraries could eventually incorporate web links to vast amounts of genome-wide, DNA-based information from reference species and thereby stimulate growth of new research and educational tools that would join the polar disciplines together. This may require a new generation of cross-disciplinary biologists and creative educators.

At the moment, evolutionary ecology provides a powerful means for elucidating the specific and variable characteristics of habitats to which a species is unable to adapt and thereby render it vulnerable to local or global extinction. However, the molecular basis for the potential vulnerability of a species is poorly understood. Phrased as a more positive question: what naturally variable genes provide a species with 'genetic resilience', by enabling it to adapt in a changing environment or to survive in a diversity of circumstances across its geographic range of habitats? In a nutshell, this question encapsulates a large gap that exists between the disciplines of molecular systems biology and evolutionary ecology, and defines molecular genetics of natural variation as a key means for bridging the gap.

\section{Converging the enquiry from polar disciplines within plant science}

Answers to this fundamental question, aimed at improving habitat conservation and species protection, will benefit from a molecular genetic approach to understanding how natural variation within wild populations enables a species to survive in increasingly variable habitats. This will require linking of our genome-wide (genomic) knowledge of organisms with an equally in-depth knowledge of suitable habitats. This approach should at the very least provide an illustrative guide to the minimal levels of genetic diversity required to sustain the survival of a species in a natural habitat, and thereby provide genetic indicators (e.g., disease resistance traits, highlighted below) for the direction and scale of public investment required for species conservation.

The Plant Kingdom provides many opportunities to probe this question. We can see and experience the magnificence of biodiversity in vascular plants that currently exists across our planet, in vast habitats such as precious tropical rainforests or in small patches of aged meadow (Silvertown 2005). As sedentary autotrophs, plants are supreme providers of sustenance, indispensable generators of diverse microhabitats for animals and microorganisms, and the backbone of terrestrial communities. They, along with their symbioses with microorganisms, make terrestrial life possible. Thus, understanding the genetic resilience of existing plant species is vital to human survival on Earth.

To address the question posed above, we will require genetically-based insights from three aspects of natural variation for a range of contrasting plant species representing different survival strategies. These insights include: 1 . identifying the critical genes 
that are naturally variable within and among established populations of a species; 2 . mapping the allelic variation in these genes onto a geographic distribution of established populations; and 3. determining the selective factors that vary among microhabitats and drive fluctuations in natural variation in a given species.

\section{Establishing a genetic model for co-evolved plant-microbe interactions}

Since a major selective characteristic in a plant's microhabitat is often likely to be biological (e.g., symbiotic associations with parasitic or mutualistic microorganisms; Thompson 1999b; Gomulkiewicz et al. 2007), the remainder of this review considers where the natural history of $A$. thaliana and its common oomycete symbionts currently stands as an early model which a new generation of experimental botanists could soon be using to explore fundamental genetically-based questions at the forefront of conservation biology.

Host specialization is a characteristic that corresponds with a high degree of speciation in fungus-like oomycetes that cause downy mildew and white rust diseases in a wide range of plant genera (Constantinescu and Fatehi 2002; Göker et al. 2004; Riethmüller et al. 2002; Voglmayr 2008; Voglmayr and Riethmüller 2006). Speciation of these plant parasites caught the attention of botanists before biology had been transformed by genetics (Lindau 1901; Gäumann 1918). Their reports included downy mildew and white rust in A. thaliana, which was rediscovered much later in 1988 by Professor Paul H. Williams (University of Wisconsin-Madison) who was seeking a potential model for research on the molecular genetics of plant-microbe interactions (Table 1).

A visiting scientist working with Williams, Eckhard Koch, had attempted to infect $A$. thaliana with downy mildew and white rust using parasite isolates collected from brassica species but with no success because, as we can conclude with hindsight, the chosen isolates were constrained by a high degree of host preference (Fig. 1a). Williams, however, informed by his reading of the earlier German reports, was successful in acquiring support from the US National Science Foundation for a solo trip to collect A. thaliana seed and parasite material in Europe. He visited Germany,
France and England during May of 1988, and was successful in finding both downy mildew and white rust of A. thaliana in Kent (southeast England; Fig. 2) while visiting Professor Ian Crute, who had recently moved to a horticulture research institute at East Malling (now East Malling Research). Williams was unable to secure additional funding, but fortunately the seed of opportunity had been sown with both Koch (who found downy mildew on A. thaliana in Switzerland after completing his visit to UW-Madison) and Crute. They were each subsequently successful in establishing $A$. thaliana downy mildew and white rust as model pathosystems for molecular genetics research (Table 1).

With respect to the phylogenetics talks presented at the 2nd International Downy Mildew meeting by $\mathrm{M}$. Thines and reviewed by Voglmayr (2008), I will refer to the two oomycete symbionts that Williams rediscovered in Europe on A. thaliana as Hyaloperonospora arabidopsis (Gäumann 1918; Göker et al. 2004; Rehmany et al. 2000; Constantinescu and Fatehi 2002; formerly Peronospora parasitica subsp. arabidopsis; abbreviated below as $H p A$ ) causing downy mildew, and Albugo candida subsp. arabidopsis (abbreviated below as AcA) causing white rust.

Current molecular knowledge of A. thalianaoomycete symbioses has largely been constructed from genetic analyses of interactions amongst a small sample of host accessions and a highly variable but also relatively small collection of $H p A$ isolates (Holub and Beynon 1997; Slusarenko and Schlaich 2003). The $H p A$ isolate names (e.g., Emoy2) reflect their origins, predominantly from the UK, with two prefix letters that indicate the geographic source $(\mathrm{As}=$ Aspatria, Cumbria; $\mathrm{Bi}=$ Biggar, Scotland; $\mathrm{Ca}=$ Canterbury, Kent; Ed = Edinburgh, Scotland; Em = East Malling, Kent; Go = Godmersham, Kent; Hi = Hilliers arboretum, Hampshire; $\mathrm{Ma}=$ Maidstone, Kent; $\mathrm{Nu}=$ Nunnery Walks, Cumbria; Wa $=$ Wageningen, Netherlands; We = Weiningen, Switzerland), and two suffix letters indicating an accession available from $A$. thaliana stock centres suitable for cultivation of the particular isolate $(\mathrm{Co}=$ Columbia; $\mathrm{Ks}=$ Keswick- 1 ; $\mathrm{La}=$ Landsberg erecta; $\mathrm{Nd}=$ Niederzenz; Oy = Oystese; $\mathrm{Wa}=$ Wassilewskija). Most of the $H p A$ isolates currently being used in research laboratories have been refined genetically by derivation from a single oospore and maintained subsequently by propagation of asexual inoculum (Holub and Beynon 1997). 
Table 1 Two decades in the Linnaean genomics of Arabidopsis thaliana-oomycete natural history

Year Milestone References

1988 Paul Williams rediscovers downy mildew (DM) and white rust (WR) Williams, PH (personal communication); Lindau 1901; in European $A t$, following an 80 year old trail.

Gäumann 1918.

1990 Natural variation of DM resistance in At is described as a model for Koch and Slusarenko 1990. molecular genetic investigation.

1991 The DM isolate Emoy2 was borne from an oospore in a seedling of At Holub 2006. 'Columbia'. This isolate would be used to establish genetics in the organism and provide the first reference genome of downy mildew parasites in 2007.

1995 Mutation of NDR1 demonstrates that H.H. Flor's notion of disease resistance being conferred by single $R$ genes can actually be a multigenic process and involve common links in the signalling of defense against diverse pathogens. This established a precedent for using oomycete and bacterial pathogens of $A t$ in comparative laboratory experiments.

Systemic acquired resistance to bacterial disease and DM in At is found to require salicylic acid.

Natural variation in WR resistance provides a complementary model for molecular genetics of $A t$-oomycete interactions.

1996 Mutation of EDS1 demonstrates that species level barriers ('non-host' resistance) to biotrophic parasites can be amenable to mutation and genetic analysis. This gene and PAD4, which is also typically required for DM resistance in $A t$, were found to encode lipase-like proteins.

1997 The first DM resistance gene RPP5 is cloned and found to encode a Parker et al. 1997. member of the previously described TIRNBS-LRR class of cytoplasmic receptor-like proteins.

Major $R$-gene clusters revealed on four chromosomes of At using a powerful combination of recombinant inbred $A t$ populations and $\mathrm{DM}$ isolates as physiological probes to map RPP loci.

1998 The bacterial resistance genes RPS4 and RPS5 were cloned and demonstrated that non-host resistance in At can involve parasite recognition mediated by classic (receptor-like) R-genes. This established the use of a broadly virulent pathogen as a surrogate vector for transient expression to test the 'non-host' recognition of effector proteins. Interestingly, mutation of RPS5 can interfere with recognition of some DM isolates.

$R$-like homologues provide a powerful class of molecular markers for map-based new oomycete resistance genes in $A t$ and in crops such as lettuce and potato.

$R P P 8$ is cloned, and found to be a CC-NBS-LRR gene (similar to the first bacterial resistance genes described in $A t$ ) and subsequently associated with viral resistance.

The multi-copy locus RPP1 contains several DM resistance genes (TIR-NBS-LRR subclass) that differ in specificity.

DM resistance genes vary in how they confer defense via different regulatory proteins.

2000 Whole genome sequence of $A t$ is announced as a public resource. The

Holub and Beynon 1997.

Warren et al. 1998; Gassmann et al. 1999; Holub 2007; Rentel et al. 2008.

Aarts et al. 1998a, b; Botella et al. 1997; Speulman et al. 1998 .

McDowell et al. 1998; Cooley et al. 2000; Takahashi et al. 2002.

Botella et al. 1998.

Aarts et al. 1998a, b; Eulgem et al. 2004.

AGI 2000; Holub 2007.

'Linnean genomics' age of plant biology is soon launched with ARABIDOPSIS 2010, an international community effort to ascribe a function for all of the genes in At by 2010 .

A single DM resistance gene ( $R P P 7)$ can confer accumulative (salicylic acid dependent and independent) defense responses.

McDowell et al. 2000; Tör et al. 2002; Eulgem et al. 2007. 
Table 1 (continued)

Year Milestone References

DM isolates collected from At appear to be phylogenetically distinct Rehmany et al. 2000 .

from brassica isolates: referred to hence as subsp. arabidopsis

$(H p A)$ or brassica $(H p B)$.

$R P P 13$ is cloned, encoding a protein homologous to RPP8 and providing the most extreme benchmark for allelic diversification of a receptor-like gene in At.

2001 An At-Phytophthora model is described, providing Agrobacteriummediated transformation of an oomycete for host-parasite research in $A t$.

2002 'Gene-for-gene' paradigm is established in the At-HpA pathosystem. An outcross of $H p A$ enables genetic evidence for five independent At-recognizable effectors (ATR1, ATR4, ATR5, ATR8 and ATR13) that correspond with different cloned DM resistance genes.

$D M 3$ is cloned from lettuce, and found to encode a TIRNBS-LRR protein similar to several RPP genes in At.

The DM parasite of crucifer species (previously Peronospora parasitica) is renamed as Hyaloperonospora parasitica.

$S G T 1 b$ and $R A R 1 / P B S 2$ provide evidence for highly conserved regulators (also found in monocots) and the likely involvement of proteolysis in defense signalling.

A. thaliana-oomycete molecular ecology is launched.

Bittner-Eddy et al. 2000; Rose et al. 2004.

Roetschi et al. 2001.

Gunn et al. 2002.

Shen et al. 2002.

Constantinescu and Fatehi 2002.

Austin et al. 2002; Muskett et al. 2002; Tör et al. 2002; Tornero et al. 2002; Warren et al. 1999.

Damgaard and Jensen 2002.

Allen et al. 2004.

2004 The first $A t$-recognized effector (ATR13) is cloned from $H p A$ isolate Maks 9 and found to encode a small secreted protein that exhibits a high degree of sequence variation amongst UK isolates of $\mathrm{HpA}$.

An EDS1-independent WR resistance gene $(R A C 1)$ is cloned and found to encode a TIR-NBS-LRR protein.

The broad spectrum late blight resistance gene $R b$ is cloned and found Song et al. 2004 . to encode a CC-NBS-LRR protein.

2005 Enhanced downy mildew resistance (DMR) mutants are described, and launch the genetic analyses of induced accessibility for oomycete parasites in At.

2006 The first draft sequence of two oomycete genomes (Phytophthora sojae and $P h$. ramorum) is announced.

$A T R 1$ is cloned from $H p A$ Emoy2 and ignites the 'Linnean genomics' age of oomycete effector biology by revealing a conserved RxLR motif also found in ATR13, effector proteins from Phytophthora species, and secreted proteins from the human malarial pathogen Plasmodium.

2007 Draft genome sequence of $H p A$ isolate Emoy2 is released by a Phytophthora consortium.

Van Damme et al. 2005; Holub 2006.

Tyler et al. 2006 .

Rehmany et al. 2005; Holub 2007; Win et al. 2007.

Borhan et al. 2004. 
a

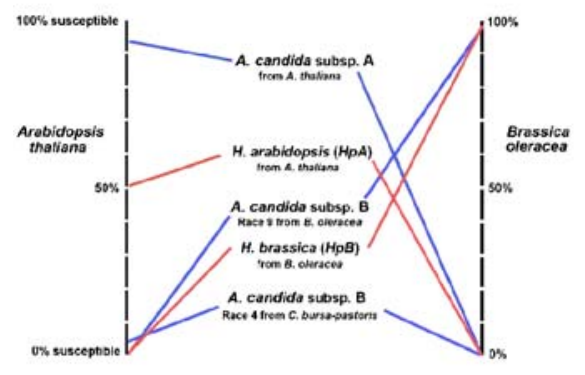

b

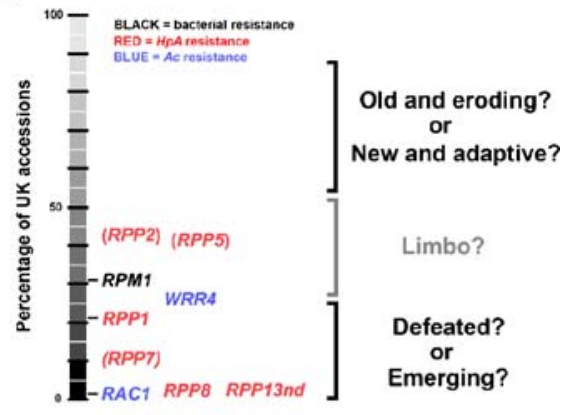

C

'Birth \& Recycling'

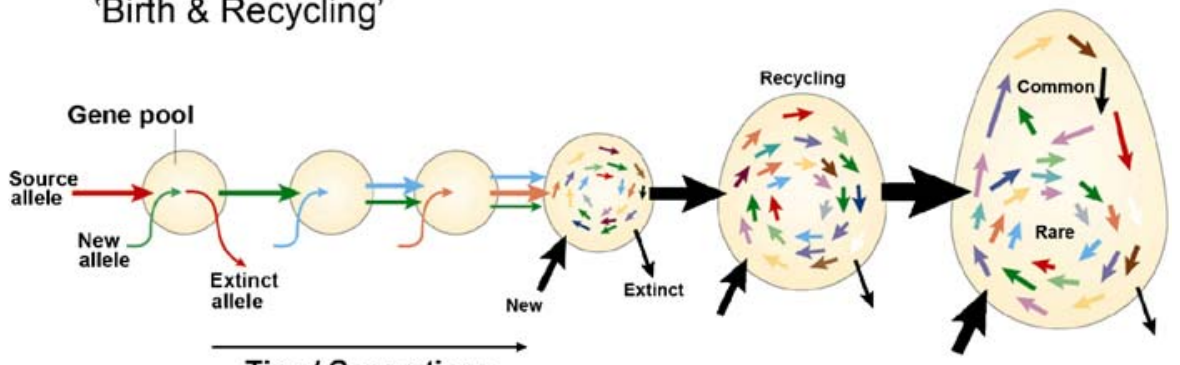

Time/ Generations

Fig. 1 Arabidopsis thaliana and its natural associations with parasitic oomycetes provide a rich and fascinating model for molecular and evolutionary ecology. Arabidopsis thaliana is a common host for two biotrophic oomycetes including Hyaloperonospora arabidopsis ( $H p A$, causing downy mildew) and Albugo candida subsp. 'A' (AcA, causing white blister rust); and will also be exposed under field conditions to recurrent but foiled attacks from closely related parasites (e.g., H. brassica and $A$. candida subsp 'B') that proliferate on brassica crops and other wild crucifers (e.g., Capsella bursa-pastoris). a The relative degree of compatibility to different parasite subspecies is compared in A. thaliana and B. oleracea; the estimates are based on the percentage of susceptibility within diversity collections of each host species (Holub et al. 1995; Holub, unpublished). b Many naturally variable pathogen recognition proteins (encoded by so-called $R$-genes) from just a few standard accessions of $A$. thaliana are now known which confer resistance to specific isolates of $H p A$ (red labels), A. candida (blue) or Pseudomonas syringae (black). All of the molecularly characterised examples are members of a large receptor-like 'NB-LRR' gene family (NB $=n$ uceotide $b$ inding site; LRR = leucine rich repeat domain; Holub 2001). Preliminary analyses (Holub unpublished) indicate that the known functional proteins occur at a frequency of $<50 \%$ in a UK diversity collection of 96 A. thaliana accessions, and many are potentially quite rare. Estimates for downy mildew and

parasitica) genes in laboratory accessions of $A$. thaliana (Holub and Beynon 1997). This HpA collection provided the 'physiological probes' for rapid, iterative mapping of numerous $R P P$ loci relative to the molecular markers already available in recombinant white rust resistance genes here have been based on cumbersome $\mathrm{F}_{2}$ allelism testing (populations derived from out-crossing UK accessions to the standard accessions containing the known $R$-genes), except where parentheses indicate cruder estimates based only on using a single standard isolate to survey resistance in the 96 accessions. These are overestimates; however, they are sufficient to pose questions (right margin) concerning the natural history of each variant R-protein, and more theoretical consideration of the origins and fate of allelic variation within a plant species. $\mathbf{c}$ For example (modified from Holub 2001), attempts to illustrate how the very earliest means of host defence (the first 'source allele'), when an ancestral host-parasite relationship began to co-evolve, may have been replaced by a 'new allele' and presumably lost from the historical DNA-based record. Several rounds of this 'arms race' may have occurred before a final solution arose in vascular plants, with a highly adaptable capability of parasite recognition made possible by the accumulation in the gene pool of allelic variation in multiple copies of highly mutable NB-LRR proteins. These proteins enable individual plants, upon parasite detection, to rapidly elicit inducible and highly conserved (ancient) defence responses. It should be possible with population-level experiments to investigate whether recycling and 'common versus rare' variants of NB-LRR proteins actually occur in the molecular ecology of $A$. thaliana-parasite interactions

inbred populations of $A$. thaliana (Holub 1997). Targets for molecular characterisation were easily established (described below) on each of the five $A$. thaliana chromosomes that represented the breadth of phenotypic variation observed in inoculated cotyledons 


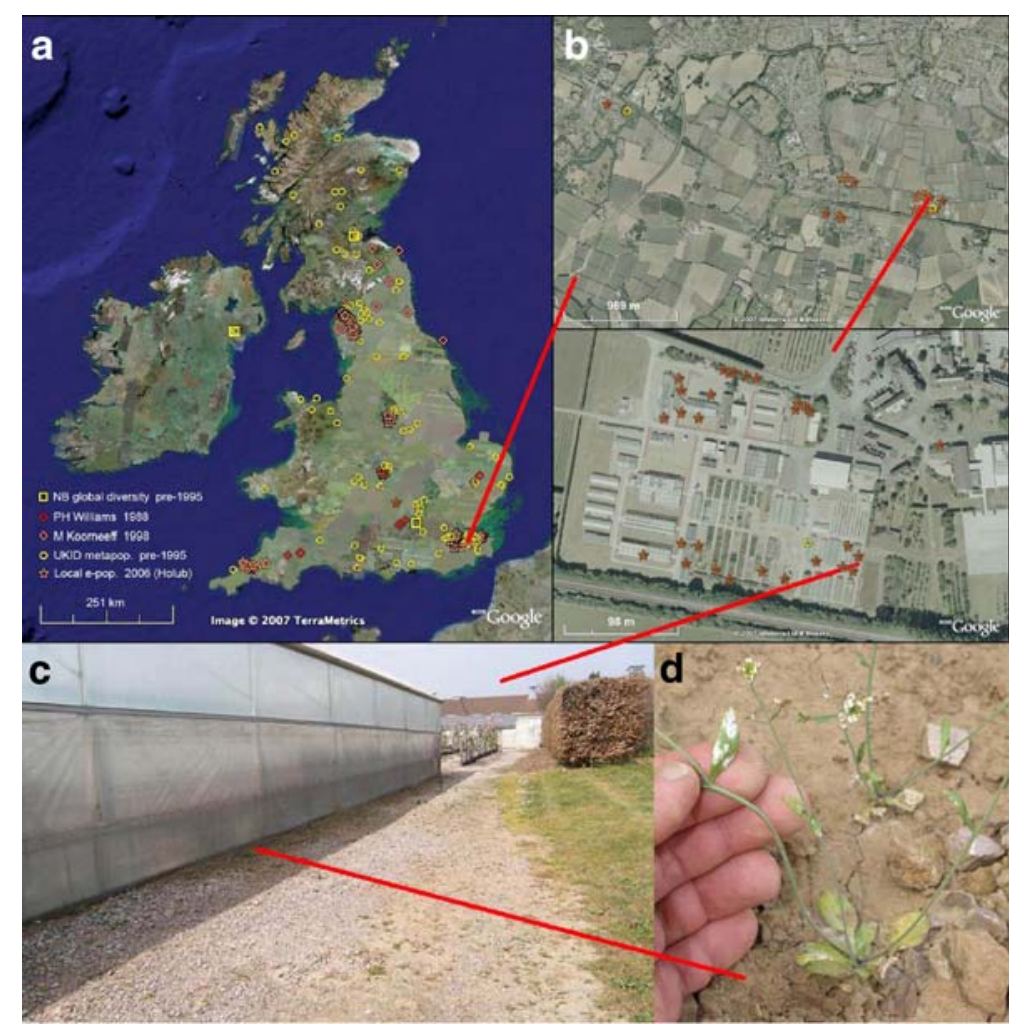

Fig. 2 The natural diversity and genomic history in Arabidopsis thaliana from the British Isles provides a unique resource for exploring molecular ecology of plants. a A large collection of A. thaliana has been assembled for a multi-national ARABIDOPSIS 2010 project which aims to generate a database of genome-wide, high density DNA sequencing from a global diversity collection of 1,152 accessions (Holub 2007). This collection includes all of the UK accessions currently available from public stock centres (Nordborg-Bergelson global diversity collection, and donations from P.H. Williams and M. Koorneeff) and a UK and Ireland diversity (UKID) collection assembled by E.B. Holub. This combined material provides a sample metapopulation of $A$. thaliana with a single accession representing the local population at each of ca. 150 locations. Extensive sampling of more than 100 established local

(Fig. 3b). It is important to note that natural variation exists in other characteristics of downy mildew or white rust resistance including: polygenic but isolatespecific in seedlings; broad spectrum in seedlings against the current $H p A$-collection; and adult leaf resistance. Although these further examples are ecologically important, they have yet to be characterised at the molecular level.

Natural variation in $A$. thaliana-AcA interactions is comparatively sparse in providing clear examples of genotype-specific resistance (Fig. 1a; Holub et al. 1995), so this closely related pathosystem was less populations ( $>10$ years old; ca. 1,200 accessions total) was conducted in 2006, and this material was also included in the first phase (low density genotyping) of the 2010 project. b Satellite photographs of one heavily sampled region in southeast England, where in 1988 P.H. Williams observed downy mildew and white blister rust in A. thaliana and where the molecular genetics of these pathosystems began 2 years later in I.R Crute's laboratory at the horticulture research facility in East Malling, Kent (aerial view of buildings, lower panel). c Epidemics have occurred most years in established $A$. thaliana populations $(>20$ years old) that reside between polytunnels. d An example of white rust occurring on rosette (readily visible above as bright yellow tissue) and stem leaves of an individual plant

attractive for the opening phase of molecular genetics research. As a consequence, this pathosystem remains undeveloped as a potentially excellent model for investigating such topics as species-level characteristics including host determinants of parasite speciation involving pathogen receptor-like genes (Fig. 1a; Rehmany et al. 2000; Borhan et al. 2008), and important aspects of compatible interactions including induced accessibility (pathogen-activated defence suppression) and source-sink dynamics affecting carbohydrate metabolism (Chou et al. 2000; Cooper et al. 2008; Holub and Cooper 2004; Tang et al. 1996). 


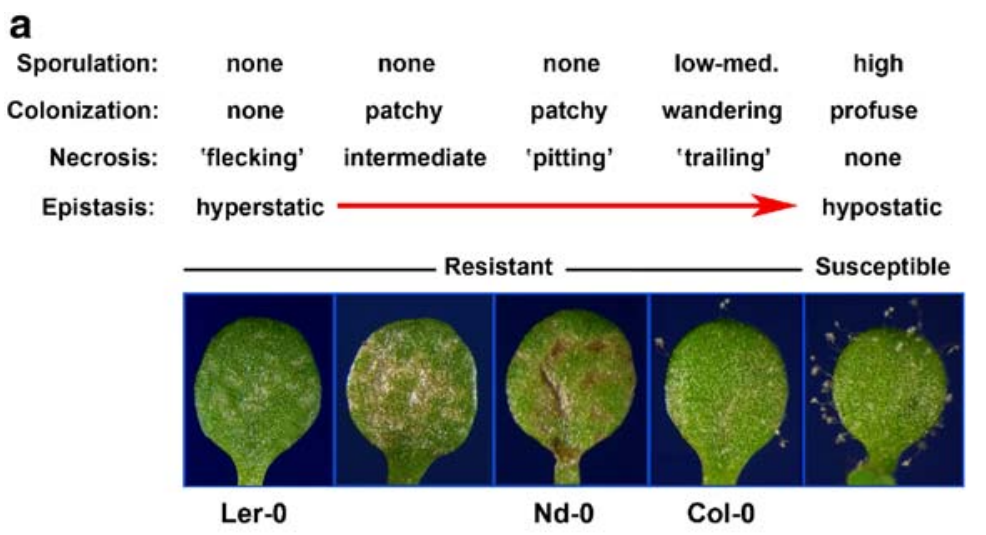

b

\begin{tabular}{|c|c|c|c|c|}
\hline Emoy2 & $\begin{array}{c}\text { RPP5 \& RPP8 } \\
\text { Chr IV \& V }\end{array}$ & $\begin{array}{l}\text { RPP1 } \\
\text { III }\end{array}$ & $\stackrel{\text { RPP4 }}{\text { IV }}$ & $\begin{array}{l}\text { transgressive } \\
\text { segregation }\end{array}$ \\
\hline Noco2 & RPP5 & $\mathbf{s}$ & $\mathbf{s}$ & \\
\hline Emco5 & RPP8 & $\begin{array}{c}\text { RPP13 } \\
\text { III }\end{array}$ & $\mathbf{s}$ & \\
\hline Emwa1 & RPP5 & $\mathbf{s}$ & RPP4 & \\
\hline Maks9 & $\underset{\mathrm{V}}{R P P 21}$ & RPP13 & $\mathbf{s}$ & \\
\hline Hiks1 & $\begin{array}{c}\text { RPP7 \& RPP27 } \\
\text { । }\end{array}$ & RPP1 & RPP7 & $\begin{array}{c}\text { transgressive } \\
\text { segregation }\end{array}$ \\
\hline Hind2 & s & $\mathbf{s}$ & $\underset{\text { II }}{R P 28}$ & \\
\hline Cala2 & $\mathbf{s}$ & $\mathbf{s}$ & $\underset{\text { IV }}{R P P 2}$ & \\
\hline Cand5 & $\mathbf{R}$ & $\mathbf{s}$ & polygenic & \\
\hline
\end{tabular}

Fig. 3 Molecular genetics has revealed tremendous diversity in the ability of Arabidopsis thaliana to recognize genetic variants of Hyaloperonospora arabidopsis ( $\mathrm{HpA}$, causing downy mildew) under laboratory conditions. Research began two decades ago (see Table 1) with a, characterisation of phenotypic variation in the incompatibility of cotyledons with respect to the extent of host colonization and sporulation by the parasite, and the relative degree of visible host response (summary text above photographs). b These interaction phenotypes were observed among several standard accessions of $A$. thaliana (e.g., Columbia, Col-0; Landsberg erecta, Ler-0; and Niederzenz, Nd-0; labelled below photographs) following inoculations with a diverse collection of $H p A$ isolates (nine examples listed in left hand column, below photos). One of the first $H p A$ isolates collected, Emoy2, is broadly avirulent and was therefore chosen for an outcross to Maks9 to launch genetic

Only two UK isolates of $A c A$ have thus far been named including the type isolate Acem1 from East Malling, Kent and Acks1 from Keswick, Cumbria (Borhan et al. 2004; Holub et al. 1995). analyses in $H p A$ (Holub 2006), and consequently, also provided DNA for the first reference genome of downy mildews. The host $\times$ parasite table (below photographs) summarizes genetic analysis of downy mildew resistance in A. thaliana conferred by $R P P$ genes (recognition of Peronospora parasitica, the previous name of $H p A$ ). Examples have been found on each of the five chromosomes of $A$. thaliana, and most of them have been molecularly characterised (RPP21 and RPP27 are exceptions). Five of them correspond with simply inherited avirulence (shown in grey box) in $H p A$, suggesting that the 'gene-for-gene' hypothesis is often valid in this pathosystem (Table 1). Susceptibility to some isolates (e.g., Emoy2 and Hiks1) was only observed in these experiments from transgressive segregation within host populations derived by intercrossing Col-0 with either Ler- 0 or $\mathrm{Nd}-0$

From a laboratory perspective, downy mildew and white rust are most detrimental to wild-type $A$. thaliana when infections are initiated at the seedling stage in a susceptible host accession. Seedlings and 
juvenile rosettes can readily succumb to downy mildew or white rust, becoming chlorotic and stunted but plants are still capable of reproducing (albeit at severely reduced capacity). As plants get older, they are generally more able to 'outgrow' downy mildew or white rust infections with no obvious developmental effects, although the parasites themselves are able to survive endophytically (without symptoms) in older tissue of a compatible host. This suggests that under natural conditions, selection pressure by $H p A$ and $A c A$ will be most acute during the establishment and competition amongst early juvenile rosettes in wild populations of A. thaliana, because debilitated plants may be less able to compete for resources with other non-diseased plants as well as being potentially more vulnerable to attack by secondary pathogens and saprophytes and more attractive to herbivores such as slugs and snails.

Using this rationale, the knowledge gained from molecular genetic analyses of downy mildew and white rust resistance in the cotyledon and seedling stage of $A$. thaliana should be relevant to theoretical considerations of host-parasite co-evolution (Fig. 1c). However, endophytic survival of $A c A$ and $H p A$ throughout the life cycle of $A$. thaliana requires consideration in future studies in molecular ecology aimed at resolving the underlying selection drivers determining the observed distribution, epidemiology and maintenance of genetic variation in these symbiotic oomycetes. Similarly, host determinants of $H p A$ and $A c A$ endophytism should also be targeted for molecular investigation; for instance, transgressive segregation for natural variation in $A$. thaliana can generate recombinant plants which exhibit hyper-susceptibility to downy mildew and white rust (high levels of sporulation and severe stunting) following inoculation of mature rosettes (Holub, unpublished). Such recombinants can presumably arise in natural populations but are presumably poor competitors when disease is prevalent and perhaps also under seemingly disease-free conditions.

\section{Two decades in the Linnaean genomics of A. thaliana}

Molecular milestones from A. thaliana-oomycete pathology have added appreciably to the Linnaean-like effort to name and classify gene families (Table 1; Holub 2001, 2006, 2007). For example, naturally variable genes that control $H p A$ isolate specific downy mildew resistance were among the first pathogen recognition genes (so-called $R$-genes) to be molecularly characterised from plants. These abundant genes in monocots and dicots encode receptor-like proteins characterised by a leucine-rich repeat (LRR) domain that is typically highly mutable, and most known $R$ genes also contain a nucleotide binding (NB) site. A single accession of $A$. thaliana will contain more than 100 full length NB-LRR genes, many of which exhibit unusually high levels of allelic variation amongst accessions of the species collected from natural populations (Borevitz et al. 2007; Clark et al. 2007; Holub 2001). At least 10 such genes have been identified as genes conferring either downy mildew or white rust resistance and are distributed amongst each of the five $A$. thaliana chromosomes; at least half reside in major $R$-like gene clusters (Borhan et al. 2004, 2008; Holub 1997, 2001).

Laboratory researchers excelled at using artificial variation generated randomly by irradiation and chemical mutagenesis to reveal other key components of induced defence (Table 1). These components (e.g., EDS1, NDR1, RAR1/PBS2 and SGT1b) represent much smaller gene families more highly conserved than $R$-genes. Such genes have been shown to be essential for defence against a wide spectrum of pathogens, as first demonstrated by the discovery of $N D R 1$, essential for resistance to plant pathogenic bacteria and downy mildew. Some of these genes have also been shown to represent essential and commonly-occurring components of induced defence across different families of vascular plants including monocots (e.g., RAR1/PBS2 and SGT1b).

It is important to remember that all of these innate defence genes, as with $R$-genes, have been identified and defined functionally in an experimental context. Each gene was discoverable because they were nonlethal and non-redundant (unique functional copy) in the specific combination of host and parasite genotypes selected by investigators for mutagenesis experiments. For instance, null mutation of $s g t 1 b$ exhibits full susceptibility to some $H p A$ isolates (e.g., Cala2) in some genetic backgrounds of $A$. thaliana including the most popular laboratory accession Columbia (Tör et al. 2002). However, the same mutant exhibits residual resistance to other isolates of $\mathrm{HpA}$ and strong resistance to all bacterial isolates tested thus far. Similarly, the effect of sgtlb mutation can also be masked in other genetic backgrounds such 
as Landsberg erecta in an RPP-dependent manner (Tör et al. 2002). This effect may be due in some cases to redundant expression of a second copy of the gene (SGT1A) known to exist in Columbia $A$. thaliana, although this hypothesis is difficult to test decisively because double mutation of the gene pair (sgtla/ sgt1b) appears to be lethal (Azevedo et al. 2006; Holt et al. 2005).

In other words, the currently known $R$-genes and other defence components were essentially 'low hanging fruit' for discovery because, despite fortuitous examples like $S G T 1 b$, functional redundancy and mutational lethality present major obstacles that limit the scope of an approach to the dissection of defence mechanisms in plants based purely on molecular genetics. This is true even in the case of excellent model organisms like $A$. thaliana. The science has nevertheless progressed a long way towards addressing Albert Ellingboe's challenge to identify the molecular 'pieces of the (disease resistance) puzzle' with genetics and mutational analyses (Ellingboe 1976, 2001; Holub 2006). Now however, complementary methods and techniques are required to extend knowledge incrementally from the low hanging fruit and fully reconstruct defence mechanisms in model systems (Glazebrook 2007; Kazan and Schenk 2007; Shen and Schulze-Lefert 2007; Staal and Dixelius 2007).

Nevertheless, for the purposes of this review, there is already sufficient molecular understanding of downy mildew resistance in A. thaliana to state what now seem to be three features underlying innate immunity in plants: (1) disease resistance typically involves the activation of an inducible defence process involving many other genes; (2) natural genetic variation in disease resistance is most prevalent at the level of receptor-like proteins (containing a highly mutable leucine-rich repeat domain), which acts as a trigger for the induced defence; and (3) exceptions to the above will arise from further investigation as a consequence of genetic background, plant tissue type and/or physiological age of tissue.

Linnaean genomics has also revolutionized our understanding of plant pathogenic oomycetes as a consequence of whole genome sequences that have become available for several Phytophthora species and $H p A$ (Table 1). There is now a fervent interest in revealing so-called effector proteins from parasitic microorganisms that somehow affect biochemical responses in a potential plant host (Grant et al. 2006; Kamoun 2007; Tör 2008; Win et al. 2007). Microbial effectors that can be detected by matching R-protein activity were previously referred to in plant pathology literature as avirulence proteins or racespecific elicitors. Similarly, non-specific elicitors have come in recent years to be referred to as PAMPs (pathogen associated molecular patterns), an abbreviated term adopted from the research literature of innate immunity in animals. Many ATR (A. thaliana recognized) effectors were predicted in $H p A$ following the genetic identification of numerous $R$-genes conferring downy mildew resistance in A. thaliana and classical genetic analysis of avirulence in Bremia lactuca (Holub and Beynon 1997; Michelmore and Wong 2008). However, confirmation of a 'gene-forgene' correspondence has only recently been confirmed for five cloned RPP genes, followed swiftly by the molecular identification of the first two ATR effectors (Table 1; Fig. 3b; reviewed by Holub 2007).

Downy mildew research in A. thaliana has benefited enormously over nearly two decades from healthy competition and collaboration amongst several research groups. However, our current knowledge (summarized in Table 1) would not have been achieved so quickly and coincident with the precedents from molecular investigations of bacterial resistance in $A$. thaliana without the original catalytic fieldwork provided by $\mathrm{P}$. H. Williams in 1988. Two downy mildew resistance genes (RPP1 and RPP5) would probably have been discovered; however, $H p A$ genetics and cloning of $H p A$ effectors would still only be a theoretical prospect if Williams had not conducted his European collection trip. Similarly, the involvement of major defence components such as EDS1, NDR1 and SGT1b in bacterial resistance would have been revealed but the parallel with downy mildew resistance would likely have come much later. Hence, Williams provided a crucial link between the founders of experimental botany and the modern laboratories of molecular plant pathologists.

\section{Establishing an experimental basis for molecular ecology of plant-parasite interactions}

Arabidopsis thaliana-oomycete symbioses could provide the basis for making the next crucial link, between recent laboratory advances in molecular 
biology of innate immunity in plants and genomicsbased field experiments of molecular ecology (Holub 2007). Seven key resources will be: (1) access to microhabitats in the form of reasonably protected field locations that have been inhabited naturally by A. thaliana; (2) seed samples from these reference habitats collected from a high proportion of individuals at each location; (3) 'DNA finger-printing' of individuals derived from these initial seed lines involving genome-extensive sequence information to provide a base-line reference for future sampling; (4) access to comparable locations uninhabited by $A$. thaliana for hypothesis testing in future seed introduction experiments (including virgin sites which could provide suitable conditions for A. thaliana, and sites which are unsuitable for some unknown selective factor despite the initial appearance of the habitat); (5) satellite navigation (GPS) and photographic records enabling field biologists to accurately re-visit the marked populations; (6) public participation that must include land owners of reference sites, local and regional plant ecologists, and amateur naturalists; and (7) online access for researchers and educators to the public-sponsored data.

The best reference locations for field research will have been well-established ( $>10$ years old, but ideally much older) natural populations of $A$. thaliana. In the British Isles for instance, $A$. thaliana is predominantly a winter annual (flowering May-June) throughout, but it can occur as a summer-autumn annual especially in wettest regions such as the Scottish highlands and the Hebrides (or even well-watered gardens with good slug control). The species relies largely on animals for seed dispersal to establish new populations, and human activity is particularly important so suitable locations for established populations will often be of man-made origin. Sites that support enduring natural populations of $A$. thaliana will include mural communities (described by Segal (1969) as vertical, such as the head, vertical face and foot of old stone or brick walls; and horizontal, such as cracks in urban pavements), ballast of disused and existing steam railway tracks, roadside verges, and cultivated areas such as historic gardens (Fig. 4).

All such habitats can be found throughout the British Isles, and even within regions such as the Lake District National Park that became a protected conservation area thanks to the investment and leadership of Beatrix Potter (Holub 2007; Thompson
2007). It will be fascinating to see whether the rich genomic history (DNA-based, whole genome) that is currently being accumulated from A. thaliana (Borevitz et al. 2007; Clark et al. 2007; Holub 2007) will enable us to resolve whether this species is a native in the British Isles or instead an archaeophyte (i.e., pre-Medieval introduction by one or more human migrations) like its close relative Capsella bursa-pastoris (Preston et al. 2004).

Mural populations of $A$. thaliana will be particularly interesting for molecular ecology, especially where A. thaliana can cycle continuously in consecutive years in essentially the same spot (Fig. 4a and b). Human disturbance represents a major threat to the survival of these self-maintaining mural populations. The linear nature of old wall and railway habitats provides pertinent opportunities to assess the accumulation and maintenance of genetic variation. It should be possible to collect evidence for multiple migration events or out-cross pollination events, as well as for genetic differences that correlate with contrasting features of microhabitat (e.g., heavy shade vs. full sunlight along a wall extending several kilometre; different exposure levels to atmospheric pollutants), and for possibly predicting historical movement of genetic variants along a wall. Although A. thaliana is highly self-fertile, pollen dispersal and outcrossing may be more important than expected for movement and maintenance of natural variation within established populations (Bakker et al. 2006), especially on walls.

In a given region, the total available length of wall habitats will far exceed the natural distribution of $A$. thaliana, so with appropriate permission from property owners, there is excellent potential for experimental introductions such as reciprocal transplants of seed from genetically distinct populations or 'seeding' of apparently non-diseased populations with oospores of genetically defined $H p A$ or $A c A$ isolates. Defining the suitable environmental conditions for establishment and extended survival of $A$. thaliana in these natural habitats will, at the very least, be critical for judging the relative merits of experiments that are performed under controlled laboratory conditions, and whether sites chosen for 'common garden studies' (Mitchell-Olds and Schmitt 2006) are representative of habitat in a given geographic region.

In the British Isles, a good start has been made in assembling the key resources outlined above. A 

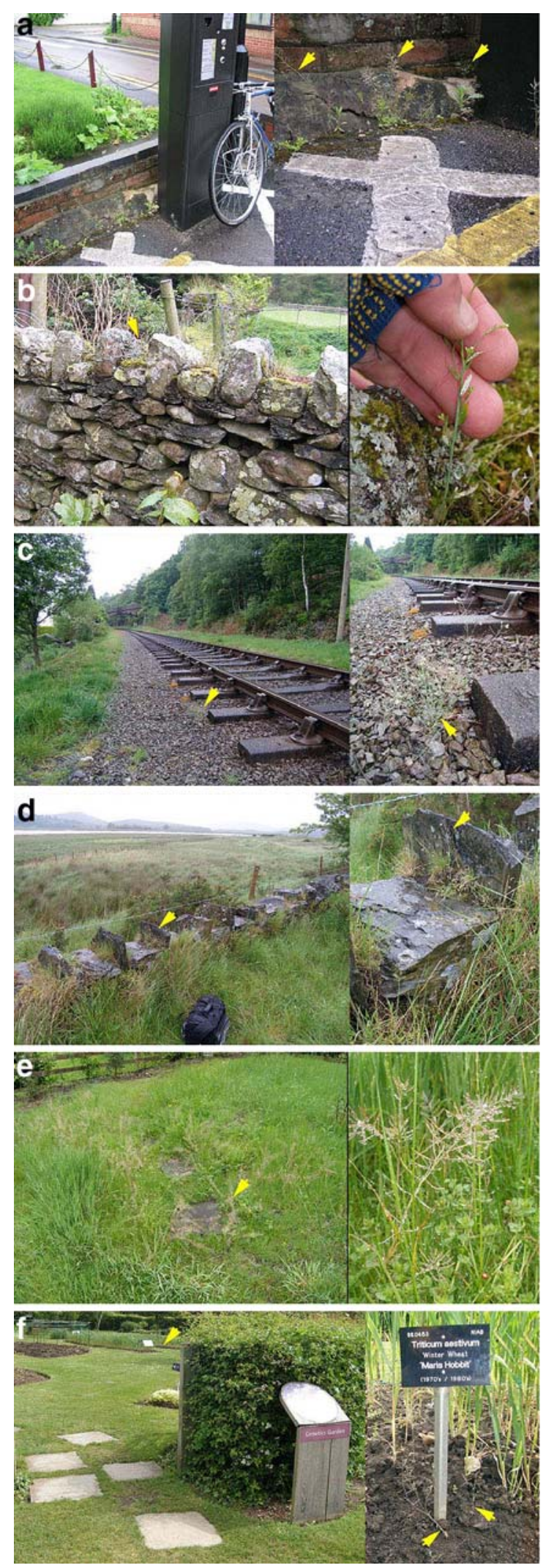

4 Fig. 4 Arabidopsis thaliana habitats are typically of man-made origin in the British Isles including: a in the cracks of pavements; b on the head, vertical face and foot of old stone or brick walls; $\mathbf{c}$ in the ballast of existing steam railway tracks, d persisting in disused sections of railways; e in grassland meadows and roadside verges; and $\mathbf{f}$ in cultivated settings (e.g., a flower bed in the Cambridge University Botanical garden). The resident populations are typically well established in these locations; for example, ' $\mathrm{X}$ ' literally marks the spot in a where three to five plants reside annually at this location on a street in Stratford-on-Avon, and similarly in $\mathbf{b}$ for the position on top of a drystone wall in the Lake District. White blister rust (Albugo candida subsp. A) is the disease most commonly visible during late spring in UK habitats (example shown in $\mathbf{b}$, right panel); however, downy mildew (Hyaloperonospora arabidopsis) can also occur frequently during the juvenile rosette stage (October-March). Yellow arrowheads indicate the location of $A$. thaliana plants in each of these habitats

starter set of $A$. thaliana accessions has been available from public stock centres, and this has been extended with a metapopulation sample that was assembled over 5 years between 1988 and 1993 (Fig. 2a). The local population at each of the locations is represented by a single accession (seed from one individual). In 2006, GPS marking was initiated of field sites that were inhabited with established populations of $A$. thaliana, and seed was collected from at least five individuals per population $(80 \%$ or more of individuals in each population; ca. 1,200 samples in total). Many of the sites had been sampled in previous forays, including wall populations in southeast England that P.H. Williams had visited in 1988. In most cases, populations were found in the same site as in previous forays indicating an age of at least 1520 years. Such walls are often more than 100 years old. Many of the newly identified sites from 2006 were subsequently revisited in 2007 to confirm that the populations were also recurrent. Unfortunately, given the timing and logistics of handling seed samples, it was not possible to thoroughly assess disease and collect pathogen samples. The sole purpose was to accumulate potential sites of scientific interest and reference host material. Nonetheless, AcA was observed in ca. $70 \%$ of the established populations in both the spring of 2006 and 2007 (e.g., Figs. $2 \mathrm{~d}$ and $4 \mathrm{~b}$ ), whereas $H p A$ was only found in a few locations $(<2 \%)$. These observations at least identify sites for future host-parasite investigations.

For DNA fingerprinting, the complete collection of A. thaliana from the British Isles shown in Fig. 2a has been incorporated into a major international project led by US scientists, including sampling from 
established populations in 2006 (Holub 2007). This project is aimed at providing laboratory researchers with a global diversity collection of 1,152 accessions, a large database of molecular markers $(<10 \mathrm{~kb}$ spacing), and linkage analysis tools as a research capability for the mapping of genes that underlie natural phenotypic variation in A. thaliana. The first phase of the project, however, was to genotype more than 5,000 accessions (mostly European and USA samples) at 149 genome-wide loci containing SNP (single nucleotide polymorphism) or indel (small insertion or deletions) sequence variation. This relatively low-cost dataset provides a means for choosing accessions with unique genotypes that represent global diversity in an elite collection that will undergo the further high-density genotyping. All of the British accessions have been genotyped in the first phase, and ca. $20 \%$ are likely to be advanced for inclusion in the elite diversity collection. The low-density genotyping should provide sufficient information for assessing the frequency and distribution of genetic variation in UK A. thaliana at different geographic scales and in contrasting habitats, and for choosing prime diseased and non-diseased sites for future field research.

Access to A. thaliana seed stocks and DNA information will be possible via the North American and European stock centres (www.biosci.ohio-state.edu/ pcmb/Facilities/abrc/abrchome.htm; www.arabidopsis. info) and the central information website (www. arabidopsis.org). The UK National Biodiversity Network (www.nbn.org.uk) provides an exciting precedent for international efforts to release biodiversity information online, and will therefore provide a superb means for releasing information about reference field sites for A. thaliana in the British Isles.

\section{Pump-priming molecular pathology in natural populations of $\boldsymbol{A}$. thaliana}

Although the seven key resources described above are at various stages of development, it is already possible to envisage how the molecular ecology of A. thaliana-parasite interactions will begin to unfold.

For instance, the conventional method of using standard parasite isolates (diagnostic for different $R$ genes) to assess wild accessions for compatibility phenotypes indicates that most of the currently known $R$-genes, conferring bacterial or oomycete resistance, occur across the UK at a frequency well below $50 \%$. This may suggest that the resistance alleles are transient, and are either newly-emergent alleles that have yet to provide a selective advantage under natural conditions, or are much older alleles that have been persistently defeated by a virulent pathogen across the species distribution (Fig. 1b). Alternatively, they may be relatively old alleles that have been recycled by undergoing fluctuations in frequency due to changes in virulence of the pathogen population (Fig. 1c; Holub 2001).

These hypotheses need testing by spatial and temporal experiments in populations of $A$. thaliana and should be extended to include other ecologically relevant examples of natural variation (e.g., polygenic and adult plant resistance). Seedling assays with $\mathrm{HpA}$ and $A c A$ isolates provide a simple and high-throughput means of generating phenotypic data (Fig. 5); however the results obtained will lack precision for genotyping purposes because uncharacterised R-protein/avirulent effector interactions may occur in the sampled material which can confound interpretations from the observed phenotypes. Additional data generated from bacterial assays may eventually be possible, using a broadly virulent isolate of Pseudomonas syringae as genetically engineered physiological probes to predictably deliver different avirulent effectors from downy mildew and white rust parasites (Holub 1997, 2007; Rentel et al. 2008).

The next step will be to generate phenotypic data using the existing UK seed stocks and remaining elite global diversity collection, to supplement the rich DNA-based dataset. Once the prime reference locations have been identified, the major investigation can commence with experiments designed to monitor changes in known $R$-genes and oomycete effectors. Low-cost genotyping and PCR-based assays that can be used to detect specific alleles will be instrumental as case studies in aiding progress, especially at fine levels of spatial distribution where populations may have, for example, extended along a kilometre or more of wall and are exposed to variable physical and biological conditions of microhabitat.

\section{Concluding remarks}

The natural history of $A$. thaliana-oomycete interactions was the topic of a reviews published a decade 
Subpop.
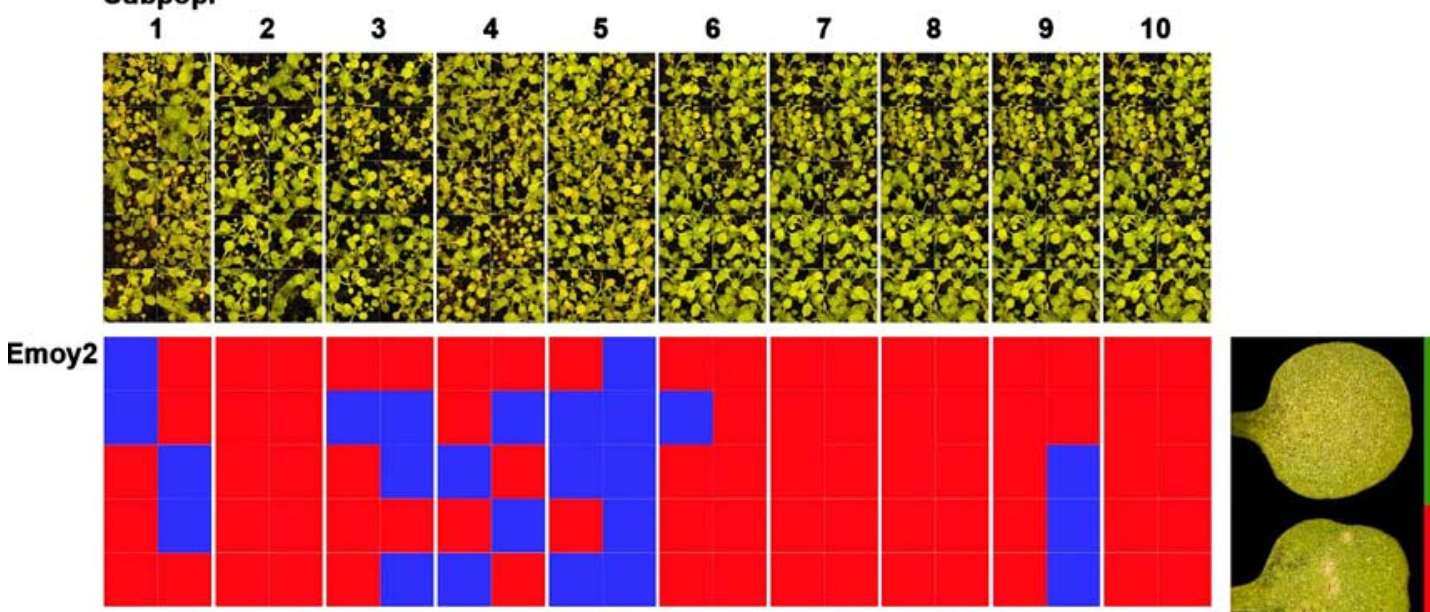

Green

Turgid
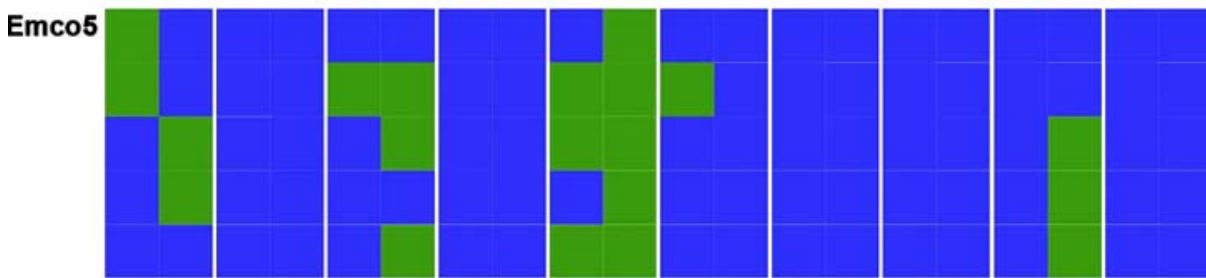

Hiks1
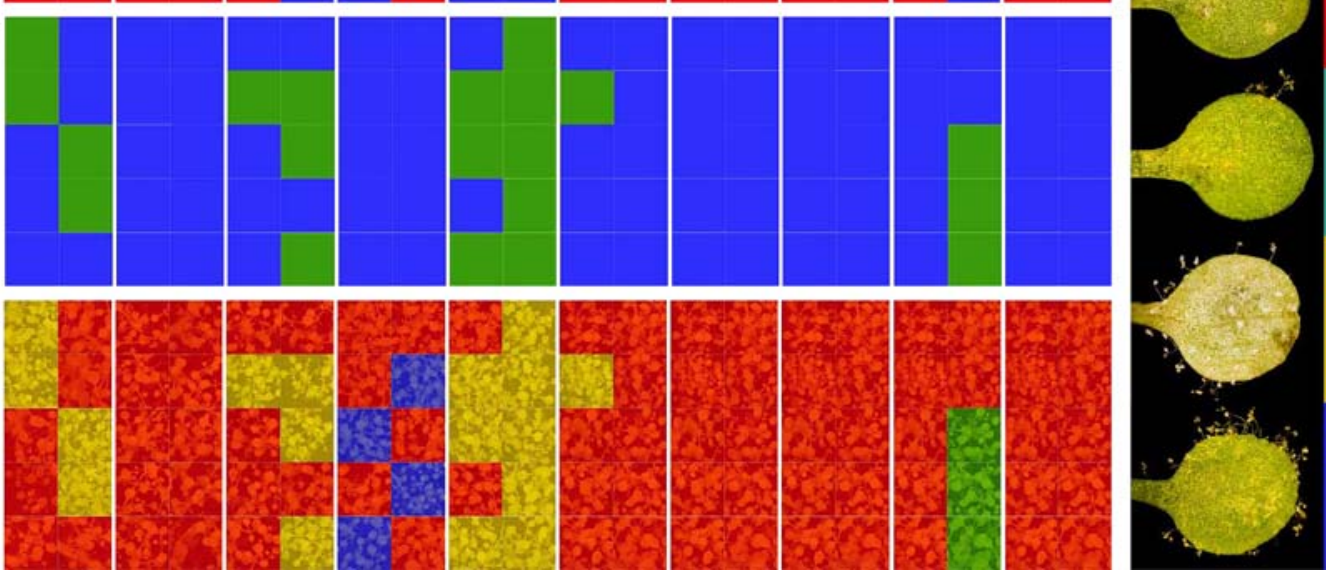

No DM

Fig. 5 Arabidopsis thaliana from the grounds of a horticulture research site in southeast England (located at East Malling Research) provides one important example of a well-established wild population (at least 25 years old) for investigating the molecular ecology of downy mildew. The reference isolate of Hyaloperonospora arabidopsis (HpA-Emoy2) was derived in 1991 from oospore-infested leaf tissue, collected from $A$. thaliana plants that were growing naturally outside a polytunnel at this location (Holub 2006; see Fig. 2c). Seed samples were subsequently collected in 1993, from 200 plants that were distributed across the research site, and each seed line was increased by selfpollination to establish larger individual seed stocks of this sample population for use in laboratory experiments. In a pilot experiment, 100 seed lines (arranged as illustrated by top row of seedling photographs; divided in 10 subpopulations of 10 lines in each) were inoculated as 7 day-old seedlings with different $\mathrm{HpA}$ isolates including Emoy2, Emoc5 (also from the same East Malling site), and Hiks1 (from Hampshire, ca. $250 \mathrm{~km}$ west of East Malling). Interaction phenotypes (far right, vertical panel of cotyledon photographs, along with brief description and colour

ago (Holub 1997; Holub and Beynon 1997). However, the emphasis then was on laboratory research and the 'hardcore' molecular biology of innate immunity in plants. Molecular ecology of plant-parasite inter- coding) were recorded for each combination of seed line and $H p A$ isolate. The pattern of colour coding summarizes the observed phenotype from each combination (seed line $\times$ isolate) across the host population. The red phenotype is specifically indicative of downy mildew resistance mediated by RPP1 on chromosome 3 (recognizing both Emoy2 and Hiks1), and appears to occur at a high frequency throughout this population. The only alternative phenotype observed with Emoy2 was full susceptibility, whereas two alternative resistance phenotypes were observed with Hiks1; the $R P P$ gene(s) conferring these examples of resistance have yet to be determined. Interestingly, Emco5 inoculations revealed an opposite pattern of susceptibility and resistance compared with Emoy2. In this case, the GREEN or full immunity phenotype may be indicative of RPP13 which is known to recognize Emco5 and is closely linked to RPP1; however, this too has yet to be determined). Nonetheless, these preliminary data indicate that two of the most important $R P P$ genes from previous laboratory research most likely occur in this natural population of $A$. thaliana as well as the matching avirulence effectors within the resident $H p A$ population

actions at that time was an aspiration for a small community of biologists. Times have clearly changed with the complete genome sequence of the first $A$. thaliana accession, rich DNA-sequence data from 
another $20 \mathrm{~A}$. thaliana accessions (Borevitz et al. 2007; Clark et al. 2007), and a dramatic fall in the cost of DNA sequencing. The aspiration has progressed from plausibility to a very real and exciting opportunity.

Much of the infrastructure is falling into place, behind major advances in the molecular genetics of downy mildew resistance in $A$. thaliana over the past two decades, and the discovery of large numbers of oomycete effectors providing raw material for another complementary round of investigation in the downy mildew parasites of $A$. thaliana and crops such as lettuce (Michelmore and Wong 2008; Tör 2008; Win et al. 2007). In parallel, the infrastructure for $A$. thaliana field biology is beginning to emerge, which has exciting potential for advancements in understanding the evolutionary context of a range of developmental and physiological processes in plants.

The well-developed and timely geographic mosaic theory of co-evolution provides the essential framework for constructive use of the resources described in this review. Mathematical modelling that combines ecological parameters (to explain spatial and temporal changes in populations) with evolutionary genetics (natural selection acting on multiple loci of interacting species) represents an enormous challenge for this exciting research field. However, a cross-disciplinary 'systems biology' approach is inevitable. Somehow, all of the public investment in laboratory research of A. thaliana will not make sense without further practical applications in plant breeding, and equally, without concerted contributions from a new generation of field botanists who are committed to aiding conservation biology. I would hope that the likes of A. DeBary and H.M. Ward would agree.

Acknowledgements The author is grateful to Robin Allaby, Simon Bright, Ian Crute, Greg Gilbert, Cindy Morris and Caroline Young for critical reading of the manuscript; to Joy Bergelson for the opportunity to join the 2010 association mapping project; and for generous support for related research from the UK Biotechnology and Biological Sciences Research Council and the Gatsby Charitable Trust.

\section{References}

Aarts, M. G. M., Hekkert, B. L., Holub, E. B., Beynon, J. L., Stiekema, W. J., \& Pereira, A. (1998a). Identification of Rgene homologous DNA fragments genetically linked to disease resistance loci in Arabidopsis thaliana. Molecular Plant-Microbe Interactions, 11, 251-258.
Aarts, N., Metz, M., Holub, E. B., Staskawicz, B. J., Daniels, M. J., \& Parker, J. E. (1998b). Different requirements for EDS1 and NDR1 by disease resistance genes define at least two $R$ gene-mediated signalling pathways in Arabidopsis. Proceedings of the National Academy of Science, USA, 95, 10306-10311.

Allen, R. L., Bittner-Eddy, P. D., Grenville-Briggs, L. J., Meitz, J. C., Rehmany, A. P., Rose, L. E., et al. (2004). Hostparasite coevolutionary conflict between Arabidopsis and downy mildew. Science, 306, 1957-1960.

Arabidopsis Genome Initiative (2000). Analysis of the genome sequence of the flowering plant Arabidopsis thaliana. Nature, 408, 796-815.

Austin, M. J., Muskett, P., Kahn, K., Feys, B. J., Jones, J. D., \& Parker, J. E. (2002). Regulatory role of SGT1 in early R gene-mediated plant defences. Science, 15, 2077-2080.

Ayers, P. (2005). The fungal thread of death p. 168. St Paul, MN, USA: American Phytopathological Society Press.

Azevedo, C., Betsuyaku, S., Peart, J., Takahashi, A., Noël, L., Sadanandom, A., et al. (2006). Role of SGT1 in resistance protein accumulation in plant immunity. The EMBO Journal, 25, 2007-2016.

Bakker, E. G., Stahl, E. A., Toomajian, C., Nordborg, M., Krietman, M., \& Bergelson, J. (2006). Distribution of genetic variation within and among local populations of Arabidopsis thaliana over its species range. Molecular Ecology, 15, 1405-1418.

Bittner-Eddy, P. D., Crute, I. R., Holub, E. B., \& Beynon, J. L. (2000). RPP13 is a simple locus in Arabidopsis for alleles that specify downy mildew resistance to different avirulence determinants in Peronospora parasitica. The Plant Journal, 21, 177-188.

Borevitz, J. O., Hazen, S. P., Michael, T. P., Morris, G. P., Baxter, I. R., et al. (2007). Genome-wide patterns of single-feature polymorphism in Arabidopsis thaliana. Proceedings of the National Academy of Science, USA, 104, 12057-12062.

Borhan, M. H., Brose, E., Beynon, J. L., \& Holub, E. B. (2001). White rust (Albugo candida) resistance loci on three Arabidopsis chromosomes are closely linked to downy mildew (Peronospora parasitica) resistance loci. Molecular Plant Pathology, 2, 87-95.

Borhan, M. H., Gunn, N., Cooper, A., Gulden, S., Tör, M., Rimmer, S. R., et al. (2008). WRR4 encodes a TIR-NBLRR protein that confers broad spectrum white rust resistance in Arabidopsis thaliana to four physiological races of Albugo candida. Molecular Plant-Microbe Interactions, (in press).

Borhan, M. H., Holub, E. B., Beynon, J. L., Rozwadowski, K., \& Rimmer, S. R. (2004). The Arabidopsis TIR-NB-LRR gene RACl confers resistance to Albugo candida (white rust) and is dependent on EDS1 but not PAD4. Molecular Plant-Microbe Interactions, 17, 711-719.

Botella, M. A., Coleman, M. J., Hughes, D. E., Nishimura, M. T., Jones, J. D., \& Somerville, S. C. (1997). Map positions of 47 Arabidopsis sequences with sequence similarity to disease resistance genes. The Plant Journal, 12, 1197-1211.

Botella, M. A., Parker, J. E., Frost, L. N., Bittner-Eddy, P. D., Beynon, J. L., Holub, E. B., et al. (1998). Three genes of the Arabidopsis RPPI complex locus recognize distinct 
Peronospora parasitica (downy mildew) avirulence determinants. The Plant Cell, 10, 1847-1860.

Century, K. S., Holub, E. B., \& Staskawicz, B. J. (1995). $N D R 1$, a locus of Arabidopsis thaliana that is required for disease resistance to both a bacterial and a fungal pathogen. Proceedings of the National Academy of Science, USA, 92, 6597-6601.

Century, K., Shapiro, A. D., Repetti, P. P., Dahlbeck, D., Holub, E. B., \& Staskawicz, B. J. (1997). NDR1, a pathogen induced component required for Arabidopsis disease resistance. Science, 278, 1963-1965.

Chou, H.-M., Bundock, N., Rolfe, S. A., \& Scholes, J. D. (2000). Infection of Arabidopsis thaliana leaves with Albugo candida (white blister rust) causes a reprogramming of host metabolism. Molecular Plant Pathology, 1, 99-113.

Clark, R. M., Schweikert, G., Toomajian, C., Ossowski, S., Zeller, G., et al. (2007). Common sequence diversity in Arabidopsis thaliana. Science, 317, 338-342.

Cooley, M. B., Pathirana, S., Wu, H. J., Kachroo, P., \& Klessig, D. F. (2000). Members of the Arabidopsis HRT/RPP\& family of resistance genes confer resistance to both viral and oomycete pathogens. The Plant Cell, 12, 663-676.

Cooper, A. J., Latunde-Dada, A. O, Woods-Tör, A., Lynn, J., Lucas, J. A., Crute, I. R., et al. (2008). Basic compatibility of Albugo candida in Arabidopsis thaliana and Brassica juncea causes broad-spectrum suppression of innate immunity. Molecular Plant-Microbe Interactions, (in press).

Constantinescu, O., \& Fatehi, J. (2002). Peronospora-like fungi (Chromista, Peronosporales) parasitic on Brassicaceae and related hosts. Nova Hedwigia, 74, 291-338.

Damgaard, C., \& Jensen, B. D. (2002). Disease resistance in Arabidopsis thaliana increases the competitive ability and the predicted probability of long-term ecological success under disease pressure. Oikos, 98, 459-466.

Ellingboe, A. H. (1976). Genetics of host-parasite interactions. In R. Heitefuss, \& P. H. Williams (Eds.) Physiological plant pathology (Encyclopedia of plant physiology, new series, vol 4 (pp. 761-778). Berlin: Springer.

Ellingboe, A. H. (2001). Plant-pathogen interactions: Genetic and comparative analyses. European Journal of Plant Pathology, 107, 79-84.

Eulgem, T., Wang, X. J., Tsuchiya, T., Beasley, B., Tör, M., Zhu, T., et al. (2007). EDM2 is a novel component of $R P P 7-d e p e n d e n t$ disease resistance in Arabidopsis that controls RPP7 transcript levels. The Plant Journal, 49, 829-839.

Eulgem, T., Weigman, V. J., Chang, H. S., McDowell, J. M., Holub, E. B., Glazebrook, J., et al. (2004). Three genetically separable $R$ gene signaling pathways converge to regulate a largely overlapping transcriptome. Plant Physiology, 135, 1129-1144.

Falk, A., Feys, B. J., Frost, L. N., Jones, J. D., Daniels, M. J., \& Parker, J. E. (1999). EDS1, an essential component of R gene-mediated disease resistance in Arabidopsis has homology to eukaryotic lipases. Proceedings of the National Academy of Science, USA, 96, 3292-3297.

Gassmann, W., Hinsch, M. E., \& Staskawicz, B. J. (1999). The Arabidopsis RPS4 bacterial-resistance gene is a member of the TIR-NBS-LRR family of disease-resistance genes. The Plant Journal, 20, 265-277.
Gäumann, E. (1918). Ueber die Formen der Peronospora parasitica (Pers.) Fries. Beih. Bot. Zentralblatt, 35(1. Abt.), 395-533.

Glazebrook, J. (2007). Use of microarry analysis to dissect the plant defence response. Methods of Molecular Biology, $354,121-130$.

Glazebrook, J., Zook, M., Mert, F., Kagan, I., Rogers, E. E., Crute, I. R., et al. (1997). Phytoalexin-deficient mutants of Arabidopsis reveal that PAD4 encodes a regulatory factor and that four $P A D$ genes contribute to downy mildew resistance. Genetics, 146, 381-392.

Göker, M., Riethmüller, A., Voglmayr, H., Weiss, M., \& Oberwinkler, F. (2004). Phylogeny of Hyaloperonospora based on nuclear ribosomal internal transcribed spacer sequences. Mycological Progress, 3, 83-94.

Gomulkiewicz, R., Drown, D. M., Dybdahl, M. F., Godsoe, W., Nuismer, S. L., Pepin, K. M., et al. (2007). Dos and don'ts of testing the geographic mosaic theory of coevolution. Heredity, 98, 249-258.

Grant, S. R., Fisher, E. J., Chang, J. H., Mole, B. M., \& Dangl, J. L. (2006). Subterfuge and manipulation: Type III effector proteins of phytopathogenic bacteria. Annual Review of Microbiology, 60, 425-449.

Gunn, N., Byrne, J., \& Holub, E. B. (2002). Outcrossing of two homothallic isolates of Peronospora parasitica and segregation of avirulence matching six resistance loci in Arabidopsis thaliana. In P. T. N. Spencer-Phillips, U. Gisi, \& A. Lebeda (Eds.) Advances in downy mildew research (pp. 185-188). Dordrecht: Kluwer Academic Publishers.

Holt, B. F., Belkhadir, Y., \& Dangl, J. L. (2005). Antagonistic control of disease resistance protein stability in the plant immune system. Science, 309, 929-932.

Holub, E. B. (1997). Organization of resistance genes in Arabidopsis. In I. R. Crute, E. B Holub, \& J. J. Burdon (Eds.) The gene-for-gene relationship in plant parasite interactions (pp. 5-26). Wallingford, UK: CAB International.

Holub, E. B. (2001). The Arms race is ancient history in Arabidopsis, the wildflower. Nature Reviews Genetics, 2, 516-527.

Holub, E. B. (2006). Evolution of symbioses between plants and filamentous parasites. Current Opinion of Plant Biology, 9, 397-405.

Holub, E. B. (2007). Natural variation in innate immunity of a pioneer species. Current Opinion of Plant Biology, 10, 415-424.

Holub, E. B., \& Beynon, J. L. (1997). Symbiology of mouseear cress (Arabidopsis thaliana) and oomycetes. Advances in Botanical Research, 24, 227-273.

Holub, E. B., Beynon, J. L., \& Crute, I. R. (1994). Phenotypic and genotypic characterisation of interactions between isolates of Peronospora parasitica and accessions of Arabidopsis thaliana. Molecular Plant-Microbe Interactions, 7, 223-239.

Holub, E. B., Brose, E., Tör, M., Clay, C., Crute, I. R., \& Beynon, J. L. (1995). Phenotypic_and genotypic variation in the interaction between Arabidopsis thaliana and Albugo candida. Molecular Plant-Microbe Interactions, 8, 916-928.

Holub, E. B., \& Cooper, A. (2004). Matrix, reinvention in plants: How genetics is unveiling secrets from non-host disease resistance. Trends Plant Science, 9, 211-214. 
Jirage, D., Tootle, T. L., Reuber, T. L., Frost, L. N., Feys, B. J., Parker, J. E., et al. (1999). Arabidopsis thaliana PAD4 encodes a lipase-like gene that is important for salicylic acid signaling. Proceedings of the National Academy of Science, USA, 96, 13583-13588.

Jönsson, H., Heisler, M. G., Shapiro, B. E., Meyerowitz, E. M., \& Mjolsness, E. (2006). An auxin-driven polarized transport model for phyllotaxis. Proceedings National Academy of Science, USA, 103, 1633-1638.

Kamoun, S. (2007). Groovy times: Filamentous pathogen effectors revealed. Current Opinion of Plant Biology, 10, 358-365 (Aug issue).

Kazan, K., \& Schenk, P. M. (2007). Genomics in induced resistance. In D. Walters, A. Newton, \& G. Lyon (Eds.) Induced resistance for plant defence (pp. 31-64). Oxford: Blackwell.

Koch, E., \& Slusarenko, A. (1990). Arabidopsis is susceptible to infection by a downy mildew fungus. The Plant Cell, 2, $437-445$.

Lawton, K., Weymann, K., Friedrich, L., Vernooij, B., Uknes, S., \& Ryals, J. (1995). Systemic acquired resistance in Arabidopsis requires salicylic acid but not ethylene. Molecular Plant-Microbe Interactions, 8, 863-870.

Lindau, G. (1901). Hilfsbuch für das Sammein Parasitischer Pilze. Berlin: Bornträger Verlag.

McCouch, S. (2004). Diversifying selection in plant breeding. PLoS Biology, 2, 1507-1512.

McDowell, J. M., Cuzick, A., Can, C., Beynon, J. L., Dangl, J. D., \& Holub, E. B. (2000). Downy mildew (Peronospora parasitica) resistance genes in Arabidopsis vary in functional requirements for $N D R 1, E D S 1, N P R 1$, and salicylic acid accumulation. The Plant Journal, 22, 523-529.

McDowell, J. M., Dhandaydham, M., Long, T. A., Aarts, M. G. M., Goff, S., Holub, E. B., et al. (1998). Intragenic recombination and diversifying selection contribute to the evolution of downy mildew resistance at the RPP8 locus of Arabidopsis. The Plant Cell, 10, 1861-1874.

Michelmore, R. W. \& Wong, J. W. (2008). Classical and molecular genetics of Bremia lactucae, lettuce downy mildew. European Journal of Plant Pathology, (this issue).

Mitchell-Olds, T., \& Schmitt, J. (2006). Genetic mechanisms and evolutionary significance of natural variation in Arabidopsis. Nature, 441, 264-271.

Muskett, P. R., Kahn, K., Austin, M. J., Moisan, L. J., Sadanandom, A., Shirasu, K., et al. (2002). Arabidopsis RAR1 exerts rate-limiting control of $\mathrm{R}$ gene-mediated defences against multiple pathogens. The Plant Cell, 14, 979-992.

Parker, J. E., Coleman, M. J., Szado, V., Frost, L. N., Schmidt, R., van der Biezen, E. A., et al. (1997). The Arabidopsis downy mildew resistance gene RPP5 shares similarity to the Toll and interleukin-1 receptors with $N$ and L6. The Plant Cell, 9, 879-894.

Parker, J. E., Holub, E. B., Frost, L. N., Falk, A., Gunn, N. D., \& Daniels, M. J. (1996). Characterisation of eds1, a mutation in Arabidopsis suppressing resistance to Peronospora parasitica specified by several different $R P P$ genes. The Plant Cell, 8, 2033-2046.

Preston, C. D., Pearman, D. A., \& Hall, A. R. (2004). Archaeophytes in Britain. Botanical Journal of the Linnean Society, 145, 257-294.
Prusinkiewicz, P., Erasmus, Y., Lane, B., Harder, L. D., \& Coen, E. (2007). Evolution and development of inflorescence architectures. Science, 316, 1452-1456.

Rehmany, A. P., Gordon, A., Rose, L. E., Allen, R. L., Armstrong, M. R., Whisson, S. C., et al. (2005). Differential recognition of highly divergent downy mildew avirulence gene alleles by $R P P 1$ resistance genes from two Arabidopsis lines. The Plant Cell, 17, 1839-1850.

Rehmany, A. P., Lynn, J. R., Tör, M., Holub, E. B., \& Beynon, J. L. (2000). A comparison of Peronospora parasitica (downy mildew) isolates from Arabidopsis thaliana and Brassica oleracea using amplified fragment length polymorphism and internal transcribed spacer 1 sequence analyses. Fungal Genetics \& Biology, 30, 95-103.

Rentel, M. C., Leonelli, L., Dahlbeck, D., Zhao, B., \& Staskawicz, B. J. (2008). Recognition of the Hyaloperonospora parasitica effector ATR13 triggers resistance against oomycete, bacterial, and viral pathogens. Proceedings of the National Academy of Science, USA, 105, 1091-1096.

Riethmüller, A., Voglmayer, H., Göker, M., Weiß, M., \& Oberwinkler, F. (2002). Phylogenetic relationships of the downy mildew (Peronosporales) and related groups based on nuclear large subunit ribosomal DNA sequences. Mycologia, 94, 834-849.

Rose, L. E., Bittner-Eddy, P. D., Holub, E. B., Langley, C. H., Michelmore, R. W., \& Beynon, J. L. (2004). The maintenance of extreme amino acid diversity at the disease resistance gene, RPP13, in Arabidopsis. Genetics, 166, 1517-1527.

Roetschi, A., Si-Ammour, A., Belbahri, L., Mauch, F., \& Mauch-Mani, B. (2001). Characterisation of an Arabidopsis-Phytophthora pathosystem: Resistance requires a functional PAD2 gene and is independent of salicylic acid, ethylene and jasmonic acid signalling. The Plant Journal, 28, 293-305.

Segal, S. (1969). Ecological notes on wall vegetation p. 326. The Hague, Netherlands: Dr W. Junk.

Shen, K. A., Chin, D. B., Arroyo-Garcia, R., Ochoa, O. E., Lavelle, D. O., Wroblewski, T., et al. (2002). Dm3 is one member of a large constitutively expressed family of nucleotide binding site-leucine-rich repeat encoding genes. Molecular Plant-Microbe Interactions, 15, 251-261.

Shen, Q. H., \& Schulze-Lefert, P. (2007). Rumble in the nuclear jungle: Compartmentalization, trafficking and nuclear action of plant immune receptors. EMBO Journal, 26, 4293-4301.

Silvertown, J. (2005). Demons in Eden, the paradox of plant diversity. Chicago, IL, USA: University of Chicago Press (ISBN: 0-226-75771-4).

Slusarenko, A. J., \& Schlaich, N. L. (2003). Downy mildew of Arabidopsis thaliana caused by Hyaloperonospora parasitica (formerly Peronospora parasitica). Molecular Plant Pathology, 4, 159-170.

Song, J., Bradeen, J. M., Naess, S. K., Raasch, J. A., Wielgus, S. M., Haberlach, G. T., et al. (2004). Gene $R B$ cloned from Solanum bulbocastanum confers broad spectrum resistance to potato late blight. Proceedings of the National Academy of Science, USA, 100, 9128-9133.

Speulman, E., Bouchez, D., Holub, E., \& Beynon, J. (1998). Disease resistance gene homologs correlate with disease resistance loci of Arabidopsis thaliana. The Plant Journal, $14,467-474$. 
Staal, J., \& Dixelius, C. (2007). Tracing the ancient origins of plant innate immunity. Trends in Plant Science, 12, 334-342.

Takahashi, H., Miller, J., Nozaki, Y., Takeda, M., Shah, J., Hase, S., et al. (2002). RCY1, an Arabidopsis thaliana $R P P 8 / H R T$ family resistance gene, conferring resistance to Cucumber mosaic virus requires salicylic acid, ethylene and a novel signal transduction mechanism. The Plant Journal, 32, 655-667.

Tang, X., Rolfe, S. A., \& Scholes, J. D. (1996). The effect of Albugo candida (white blister rust) on the photosynthetic and carbohydrate metabolism of leaves of Arabidopsis thaliana. Plant, Cell \& Environment, 19, 967-975.

Thompson, J. N. (1999a). Specific hypotheses on the geographic mosaic of coevolution. The American Naturalist, 153, S1-S14.

Thompson, J. N. (1999b). The evolution of species interactions. Science, 284, 2116-2118.

Thompson, K. S. (2007). Beatrix Potter, conservationist. American Scientist, 95, 210-212.

Thompson, J. N., Reichman, O. J., Morin, P., Polis, G. A., Power, M. E., Sterner, R. W., et al. (2001). Frontiers of ecology. BioScience, 51, 15-24.

Tör, M. (2008). Tapping into molecular conversation between oomycete plant pathogens and their hosts. European Journal of Plant Pathology, (this issue).

Tör, M., Gordon, P., Cuzick, A., Eulgem, T., Sinapidou, E., Mert-Türk, F., et al. (2002). Arabidopsis SGT1b is required for defence signaling conferred by several downy mildew resistance genes. The Plant Cell, 14, 993-1003.

Tornero, P., Merritt, P., Sadanandom, A., Shirasu, K., Innes, R. W., \& Dangl, J. L. (2002). RAR1 and NDR1 contribute quantitatively to disease resistance in Arabidopsis, and their relative contributions are dependent on the $R$ gene assayed. The Plant Cell, 14, 1005-1015.
Tyler, B. M., Tripathy, S., Zhang, X., Dehal, P., Jiang, R. H., et al. (2006). Phytophthora genome sequences uncover evolutionary origins and mechanisms of pathogenesis. Science, 313, 1261-1266.

Van Damme, M., Andel, A., Hulbers, R. P., Panstruga, R., Weisbeek, P. J., \& Van den Ackerveken, G. (2005). Identification of Arabidopsis loci required for susceptibility to the downy mildew pathogen Hyaloperonospora parasitica. Molecular Plant-Microbe Interactions, 18, 583-592.

Voglmayr, H. (2008). Progress and challenge in systematics of downy mildews and white blister rusts: new insights from genes and morphology. European Journal of Plant Pathology, (this issue).

Voglmayr, H., \& Riethmüller, A. (2006). Phylogenetic relationships of Albugo species (white blister rusts) based on LSU rDNA sequence and oospore data. Mycological Research, 110, 75-85.

Warren, R. F., Henk, A., Mowery, P., Holub, E. B., \& Innes, R. W. (1998). A mutation within the leucine rich repeat domain of the Arabidopsis disease resistance gene RPS5 partially suppresses multiple bacterial and downy mildew resistance. The Plant Cell, 10, 1439-1452.

Warren, R. F., Merritt, P. M., Holub, E., \& Innes, R. W. (1999). Identification of three putative signal transduction genes involved in $R$ gene-specified disease resistance in Arabidopsis. Genetics, 152, 401-412.

Wilson, E. O. (1994). Naturalist p. 380. Washington D.C., USA: Island Press.

Win, J., Morgan, W., Bos, J., Krasileva, K. V., Cano, L. M., Chaparro-Garcia, A., et al. (2007). Adaptive evolution has targeted the C-terminal domain of the RXLR effectors of plant pathogenic oomycetes. The Plant Cell, 19, 23492369. 